University of Wollongong

Research Online

Faculty of Engineering and Information

Faculty of Engineering and Information

Sciences - Papers: Part A

Sciences

$1-1-2020$

Comparison of a laboratory-scale coke and a pilot-scale coke from matched coal

Hannah Lomas

Richard Roest

Adam Wells

Tizshauna Thorley

Hui Wu

University of Wollongong, hwu@uow.edu.au

See next page for additional authors

Follow this and additional works at: https://ro.uow.edu.au/eispapers

Part of the Engineering Commons, and the Science and Technology Studies Commons

Research Online is the open access institutional repository for the University of Wollongong. For further information contact the UOW Library: research-pubs@uow.edu.au 


\title{
Comparison of a laboratory-scale coke and a pilot-scale coke from matched coal
}

\author{
Abstract \\ (C) 2020 Institute of Materials, Minerals and Mining. A coke produced using a custom-built sole-heated \\ oven and a coke prepared in a pilot-scale oven from a matched coal, were compared using a range of \\ analytical techniques. The aim of this comparison was to assess to what extent the small-scale sole- \\ heated oven can successfully replicate the production of pilot-scale oven cokes, and thus be used to \\ rapidly prepare and screen a wide range of cokes for particular characteristics, e.g. abrasion resistance. \\ The techniques applied included conventional methods and novel methods developed by our research \\ team. These included microstructural and microtextural analyses of samples of each coke, and \\ tribological, scratch test and fractographic analyses, each of which elucidates different strength \\ attributes. These include microstructural weaknesses, abrasion resistance, and the strength of \\ microtextural interfaces. The level of replication achieved indicates that the sole-heated oven, used in \\ combination with an annealing step in a muffle furnace, can be beneficially used to model the pilot-scale \\ oven.

\section{Disciplines} \\ Engineering | Science and Technology Studies

\section{Publication Details} \\ Lomas, H., Roest, R., Wells, A., Thorley, T., Wu, H., Jiang, Z., Sakurovs, R., Fetscher, R., Xing, X. \& Mahoney, \\ M. (2020). Comparison of a laboratory-scale coke and a pilot-scale coke from matched coal. Ironmaking \\ and Steelmaking,

\section{Authors} \\ Hannah Lomas, Richard Roest, Adam Wells, Tizshauna Thorley, Hui Wu, Zhengyi Jiang, Richard Sakurovs, \\ Robert Fetscher, Xing Xing, and Merrick Mahoney
}




\section{Comparison of a Laboratory-Scale Coke and a Pilot-Scale Coke from Matched Coal}

Hannah Lomas ${ }^{1}$ * a, Richard Roest $^{1}$ a, Adam Wells ${ }^{1}$ a, Tizshauna Thorley $^{1}$, Hui $\mathrm{Wu}^{2}$, Zhengyi Jiang ${ }^{2}$, Richard Sakurovs ${ }^{3}$, Robert Fetscher ${ }^{1}$, Xing Xing ${ }^{4}$ and Merrick R. Mahoney ${ }^{1}$

${ }^{1}$ Centre for Ironmaking Materials Research, School of Engineering, Newcastle Institute for Energy and Resources, University of Newcastle, University Drive, Callaghan, NSW 2308, Australia

${ }^{2}$ School of Mechanical, Materials, Mechatronic and Biomedical Engineering,

University of Wollongong, Northfields Avenue, Wollongong, NSW 2522, Australia

${ }^{3}$ CSIRO Energy, 11 Julius Avenue, North Ryde, NSW 2113, Australia

${ }^{4}$ School of Materials Science and Engineering, University of New South Wales (UNSW)

Sydney, Kensington, NSW 2052, Australia

* Corresponding author. Tel.: +61 458181880

${ }^{a} \mathrm{HL}, \mathrm{RR}$ and $\mathrm{AW}$ contributed equally to this work.

E-mail address: Hannah.Lomas@newcastle.edu.au 


\section{Comparison of a Laboratory-Scale Coke and a Pilot-Scale Coke from Matched Coal}

A coke produced using a custom-built sole-heated oven and a coke prepared in a pilot-scale oven from a matched coal, were compared using a range of analytical techniques. The aim of this comparison was to assess to what extent the smallscale sole-heated oven can successfully replicate the production of pilot-scale oven cokes, and thus be used to rapidly prepare and screen a wide range of cokes for particular characteristics, for example, coke breakage behaviour and abrasion resistance. The techniques applied included conventional methods and novel methods developed by our research team. The conventional methods included microstructural and microtextural analyses of samples of each coke, to compare the total porosity, pore size distribution and coke carbon forms. The novel methods included tribological, scratch test and fractographic analysis of samples of each coke, each of which elucidates different metallurgical coke strength attributes. These techniques allowed the areas of microstructural weakness in the coke, the fracture toughness and abrasion resistance of individual coke microtextures, and the strength of the interfaces between those microtextures, to be assessed and quantified for each coke. The level of replication achieved indicates that the sole-heated oven, used in combination with an annealing step in a muffle furnace, can be beneficially used to model the pilot-scale oven.

Keywords: Coke, sole-heated oven, pilot oven, small-scale coke, coke microstructure, coke microtexture, fractography, tribology, coke abrasion, pore size distribution

\section{Introduction}

There have been numerous studies in recent years to compare the quality of coke produced in laboratory-scale coke ovens with their pilot-scale counterparts [1-5]. One of the key aims of these studies is to be able to produce and accurately assess the quality and thus the value of a coke on a substantially smaller scale, thereby reducing the quantity of coal needed to determine coke quality. This is particularly important when the quantity of coal required for pilot-scale testing is unavailable [1], for example, exploration bore core samples. The capacity of pilot-scale coke ovens is typically 
$350-400 \mathrm{~kg}[1,6]$, whereas the laboratory-scale coke ovens reported in the literature range in capacity, from $\sim 350 \mathrm{~g}[7-13]$ to $4 \mathrm{~kg}[5,14,15], 8 \mathrm{~kg}[4,16]$ and $12-13 \mathrm{~kg}[1-$ 3], to name a few examples. Each oven has a different design, resulting in different heating rates during the plastic stage of coking [4]. The heating rate during the formation of the plastic layer influences the development of the resulting coke microstructure $[4,17]$ and microtexture [18]. The difference in confining pressure also has an impact on coke microstructure development [7], and the combination of these parameters influence the coke strength after reaction (CSR) value of the coke generated [4].

CSR is one of the primary coke quality measures used by the coal and ironmaking industries [19]. It is thus the typical measure used to relate the quality of a bench-scale coke with its pilot-oven counterpart prepared from matched coal(s). The majority of studies in the literature have demonstrated that their laboratory-scale ovens are able to produce replicate cokes to those generated in pilot-scale ovens, with the CSR of the cokes produced matching (within measurement error) their pilot-scale counterparts $[1-3,5]$. Other studies echo the common knowledge that the CSR of a coke is strongly dependent on coking conditions $[4,18]$, and suggest that given the dependence of heating rate on coke oven design, it is not straightforward to produce a small scale coke with an analogous CSR to the equivalent pilot-scale coke.

In this paper, we compare the quality of a coke produced on a $350 \mathrm{~g}$ scale from a single coal with the equivalent coke produced in a $400 \mathrm{~kg}$ recovery pilot-scale oven [6]. The small-scale cokes were produced in a two-step process; (i) formation of a semicoke in a custom-built sole-heated oven, and (ii) annealing of the semi-coke in a muffle furnace to form a coke. The single coal selected for this study is of medium rank and relatively high inertinite content. Rather than measuring the CSR as an indicator of coke 
quality, we have adopted a new approach, which facilitates analysis for cases where the quantity of coke for a duplicate CSR test is not available. This approach uses a combination of both conventional and unconventional testing methods to assess coke quality. These include an examination of (i) coke microstructure by measuring the overall porosity and pore size distribution using optical image analysis, (ii) coke microtexture by quantitative assessment of the coke carbon forms, (iii) tribological testing of coke $[11,12,20,21]$, which is a technique used to investigate wear behaviour [22] and coke abrasion resistance, (iv) scratch testing of coke [11,23] and assessment of the severity of the resultant damage, and (v) fractographic analysis of coke [24-28] to identify the microstructural weaknesses and modes of fracture propagation.

Specific information can be extracted by each of the measurement techniques to enable assessment of coke quality. Optical image analysis was selected as a well-known and widely-used technique $[29,30]$ to measure coke porosity and pore size distribution. There is also potential for this technique to yield information on the pore wall size distribution and pore roundness [31]. Coke microtexture was assessed by Pearson Coal Petrography using algorithms developed to not only quantify the different classes of microtexture present but also the degree of anisotropy within each microtextural constituent on a pixel-by-pixel basis. This results in the generation of false-coloured visual reflectance maps which show the degree of anisotropy across an entire sample at a resolution of 1 micron per pixel $[23,32]$.

Tribological testing is a newly developed technique for assessment of coke abrasion resistance $[12,20]$. It is a cheaper and potentially valid alternative to tumble drum tests for assessing coke abrasion, requiring a substantially smaller quantity of coke per test. Further, the technique has been developed to allow testing at elevated temperatures of up to $950^{\circ} \mathrm{C}$ in gas controlled atmospheres [33]. Scratch testing with 
acoustic emission measurement enables the acoustics of the fractures to be linked back to the coke microtexture and/or mechanism of damage $[11,23]$. Fractographic analysis enables identification of specific microstructural and/or microtextural features responsible for the breakage of a coke specimen. Knowing the mechanism(s) of coke breakage or damage and the reasons for the damage could help to provide an input into fundamental models for predicting coke strength rather than relying on empirical comparisons between these strength values and coal properties.

These last three techniques will help to assess and compare the breakage behaviour and abrasion resistance of the small-scale and pilot-scale cokes. We expect direct examination of coke microstructure, microtexture and the factors contributing to coke breakage or abrasion to be valid alternatives to the CSR test, which is an indirect strength measure, for comparative assessment of laboratory-scale and pilot-scale cokes.

We have shown in this paper that coke from both a $400 \mathrm{~kg}$ recovery pilot-scale oven and a $350 \mathrm{~g}$ sole-heated oven are demonstrably similar (within measurement error) in microstructure, microtexture, abrasion resistance and breakage behaviour. This is despite the different heating profiles between the two ovens, i.e. the sole-heated oven heats from the bottom up, whilst the recovery pilot coke oven heats from the walls to the centre of the oven. We can thus conclude that the sole-heated oven, used in combination with an annealing step in a muffle oven, can provide guidelines as to the expected behaviour of coke produced in the pilot-scale oven. 


\section{Materials and methods}

\section{Metallurgical coal selection}

Table 1 lists the basic properties of the selected metallurgical coal used to form the cokes in this study and the ASTM indices of the pilot-scale oven coke formed from this coal. Throughout this paper, the coke formed on a small-scale using a sole-heated oven is referred to as MRLVS and the corresponding coke formed in the pilot-scale oven is referred to as MRLV. This terminology allows the cokes to be compared to the same cokes examined in our previous publications [11, 12, 23].

\section{Formation of laboratory-scale cokes using a sole-heated oven}

Coke oven feed-sized coal $(85 \%<3.35 \mathrm{~mm})$ was used as received. To standardize the moisture content, a moisture analysis was performed on a 20-25 g sample of the coal and the additional moisture required to achieve a moisture content of 5\% was calculated and added. This resulted in a dry bulk density of approximately $830 \mathrm{~kg} / \mathrm{m}^{3}$, similar to that used by MacPhee et al for their sole-heated oven coke charges [1-3], as well as our previous studies [36]. A zirconia ceramic mould was placed inside the sole-heated oven and the base was lined with three Whatman filter sheets (grade 1 cellulose filter paper with a thickness of $180 \mu \mathrm{m})$. The final coal charge, with a mass of approximately $350 \mathrm{~g}$, was placed inside the mould in the sole-heated oven (see Figures $1 \mathrm{a}$ and $1 \mathrm{~b}$ for labelled diagrams of the sole-heated oven). This was compacted until a bed height of $50 \mathrm{~mm}$ was obtained. Two filter sheets and a thin piece of kaolinite wool were placed on top of the coal charge. Then the oven lid was shut, and exhaust pipes and kaolinite wool insulation were added. The argon gas supply was set to flow through the sole heated oven at 4 $\mathrm{L} / \mathrm{min}$, and a load (lid pressure) of $1 \mathrm{kPa}$ was applied. The charge was heated using a ramp rate of $20{ }^{\circ} \mathrm{C} / \mathrm{min}$ until the oven reached $300{ }^{\circ} \mathrm{C}$. The ramp rate was then reduced to $10{ }^{\circ} \mathrm{C} / \mathrm{min}$ until the oven reached and was held at $950{ }^{\circ} \mathrm{C}$, until the temperature 
profile inside the oven was stable. The data from three thermocouples and a linear variable differential transformer was recorded using a computer software.

The next day the semi-coke formed was removed from the sole-heated oven, placed in a steel box, and the steel box was wrapped in aluminium foil to prevent ashing. It was annealed in a muffle furnace using a ramp rate of $3{ }^{\circ} \mathrm{C} / \mathrm{min}$ until the oven reached $1000{ }^{\circ} \mathrm{C}$. The temperature was held at $1000{ }^{\circ} \mathrm{C}$ for 1 hour, before cooling at a rate of $15{ }^{\circ} \mathrm{C} / \mathrm{min}$ until it dropped to $20^{\circ} \mathrm{C}$. Again a flow rate of $4 \mathrm{~L} / \mathrm{min}$ argon was utilised to prevent combustion. The coke sample was left in the oven overnight to cool before being removed. A photograph of an MRLVS coke produced using this method is shown in Figure 1c; the fissures through the coke were likely due to the release of remaining volatile matter during the annealing process.

\section{Formation of the pilot-scale oven coke}

The coke was prepared in a $400 \mathrm{~kg}$ recovery pilot-scale coke oven under the conditions shown in Table 2 [6].

\section{Preparation of polished coke samples}

Polished coke samples were prepared as per our previously reported method [12]. Briefly, three lumps of each coke were mounted in an epoxy resin mixture comprising hardener and a red pigment, to facilitate optical imaging. The set samples were then cut into 10-20 mm wide samples and cored using a bench drill with a $40 \mathrm{~mm}$ diamond coring bit attached. After remounting in resin, the samples were cut to a $10 \mathrm{~mm}$ thickness, and a Struers TegraSystem Autopolisher was used to polish the coke samples to $\mathrm{a}<3 \mu \mathrm{m}$ finish.

\section{High resolution optical microscopy}

High resolution optical micrographs were recorded using a Zeiss Axio Imager.Z1m 
microscope equipped with an automatic stage and both high and medium resolution cameras used to capture images using AxioVision software. Individual images (recorded at $5 \mathrm{x}$ magnification) were stitched together to capture a high resolution image of the entire sample using the AxioVision Mosaic software.

\section{Optical image analysis}

Optical image analysis was performed to measure the coke porosity using ImageJ software. Using the stitched optical image, from the centre of the sample, the largest square possible was used. Using Image Analysis software developed by NIH, this image was converted from a greyscale to a binary (black and white) image. The pores and walls of the cokes were then represented by black and white areas, respectively. The overall porosity was estimated using ImageJ software from the percent area of the image that was black (and above a set threshold on the greyscale). At the $5 \mathrm{x}$ magnification used to capture the images, pores with a diameter less than $12 \mu \mathrm{m}$ could not be resolved therefore the total porosity measurements only include pores greater than $12 \mu \mathrm{m}$ at the longest dimension. Since this technique measures porosity in $2 \mathrm{D}$, a distinction between open and closed porosity could not be made. N.B. Micro-computer tomography (CT) would enable such a distinction to be made in three dimensions [21, $37,38]$, but was beyond the scope of this paper. The 2D image analysis technique described above has been extensively applied and reported elsewhere [29-31]. Leica LAS V4.11 software was used to measure the area of each pore in pixels within each greyscale image. The pixel size was then used to convert the area of each pore from pixels squared $\left(\mathrm{px}^{2}\right)$ to $\mu \mathrm{m}^{2}$. A total of $\sim 1000$ pores were analysed for each of cokes MRLVS and MRLV.

\section{Coke petrography}


Coke petrographic analysis was carried out at Pearson Coal Petrography Inc. (Victoria, BC, Canada) [39]. Imaging was performed using a Zeiss reflected light microscope equipped with a rotating polarizer in the incident light path. Individual images, recorded at a resolution of 1 micron per pixel, were mosaicked together to produce an image of the entire sample. For the images presented in this paper, each pixel was false-coloured based on its anisotropy quotient (AQ), which was calculated using the formula (bireflectance/maximum reflectance) $* 10$ [40].

\section{Rotational tribological tests and coefficient of friction measurement}

Rotational ball-on-disk tribological experiments were conducted on samples of each coke using our previously established method [12]. Briefly, this method used a Rtec tribometer equipped with loading sensors $\left(\mathrm{F}_{\mathrm{x}}\right.$ : FXH-1kN-ARM-238 and $\mathrm{F}_{\mathrm{z}}$ : FZHA-1kN237) and a rotational stage. Holes were drilled into the samples to fit the rotational stage of the tribometer prior to the experiments. During testing, the stage was rotated at 13.65 $\mathrm{rpm}$ for the tests at a $14 \mathrm{~mm}$ radius from the centre, and at $11.94 \mathrm{rpm}$ at a $16 \mathrm{~mm}$ radius from the centre (these values were chosen to provide a linear speed of $20 \mathrm{~mm} / \mathrm{s}$ ). A ruby ball indenter (4 mm diameter) was in contact with and moving tangentially across the sample under a constant $80 \mathrm{~N}$ load. The duration of each test was 5 minutes. The conditions were kept constant between tests, and generated a clear wear track in the samples tested, with variations in the width and depth of the tracks visible by eye. All experiments were performed at room temperature and in the absence of added lubricant.

For each tribological test, the mean coefficient of friction (COF) was calculated from the frictional force and loading force as the test progressed, accounting for the initial frictional force when the indenter came into contact with the rotating sample, which varies depending on the angle at which the indenter comes into contact with the 
sample surface, and thus affects the applied loading force. Mean COF values were calculated for each rotational tribology test over 1 complete revolution, $30 \mathrm{~s}, 60 \mathrm{~s}, 120 \mathrm{~s}$, 180 s, 240 s, and 300 s (i.e. the total experimental duration for each sample). Six tests were conducted for each coke. The mean COF values and standard deviation between tests were calculated for each coke.

Following the tribological experiments, coke samples were analysed using high resolution optical microscopy, 3D laser scanning microscopy and scanning electron microscopy.

\section{Linear scratch tests}

Progressive loading linear scratch tests were performed on the polished coke blocks using a Revetest Xpress Plus Scratch Tester (RSX) with a spheroconical (400 $\mu \mathrm{m}$ diameter) Rockwell diamond indenter, using our previously established method [23]. The instrument was equipped with a $150 \mathrm{kHz}$ acoustic emission sensor. A photograph of a typical sample of coke MRLV used for both the rotational tribology and scratch tests is shown in Figure 2a. A photograph of the Revetest Xpress Plus Scratch Tester with a sample ready for testing is shown in Figure 2b. A loading range of 10-100 N over a scratch length of $5 \mathrm{~mm}$ and loading rate of $90 \mathrm{~N} /$ minute were previously determined to be optimal testing conditions $[11,12,23]$.

Six scratch tests were performed for each sample of each coke, with the acoustic emission and frictional force data from each test captured by a data logger. The change in frictional force as a function of the loading force, i.e. the change in the COF, indicated the energy absorbed, dispersed or emitted by the deformation, fracturing or other mechanism of damage to the coke sample during testing. Following testing, the coke samples were analysed using different analytical and imaging techniques. These 
included high resolution optical microscopy, 3D laser scanning microscopy and scanning electron microscopy. A photograph of a coke sample post rotational tribology and scratch testing is shown in Figure 2c.

\section{D laser scanning microscopy}

A Keyence 3D laser scanning microscope (VK-X100 Series) with an automatic stage was used for 3D imaging (at $200 \mathrm{x}$ magnification) following scratch testing. Individual images were stitched together to form a mosaicked image of each scratch. Optical, laser and height profile images were recorded simultaneously. Analysis of the 3D images and profiles was carried out using VK Analyser software.

\section{Scanning electron microscopy}

Samples were carbon coated using an SPI carbon coating unit and mounted onto aluminium stubs using a carbon tab. Conductive channels were added to the samples from their surface to the stub using carbon dag. Samples were then placed in an oven at $65^{\circ} \mathrm{C}$ for at least 30 minutes and stored in a desiccator until analysis.

Scanning electron microscopy (SEM) analysis was conducted at the University of Newcastle Electron Microscope and X-ray Unit. Images were recorded using a Zeiss Sigma VP Field Emission SEM equipped with a Bruker light element SSD EDS detector, using an accelerating voltage of $2-3 \mathrm{kV}$ for secondary electron images. Images of each scratch test were stitched together using GIMP software.

\section{Scratch test data analysis}

Analysis of the scratch test data was carried out by firstly calculating the COF for each data point by dividing the frictional force by the loading force, and then plotting both the percentage acoustic emission and the COF against the loading force which progressively increased from 10 to $100 \mathrm{~N}$ in each test. The graph was then divided into 
'windows', each comprising a loading force range of 10 N. Acoustic emissions from resin fracture (indicated by an acoustic emission intensity of less than $1.7 \%$ ) were not included in the analysis. The acoustic emission with the greatest intensity within each $10 \mathrm{~N}$ window was classified by the greatest reduction in COF that occurred during the acoustic emission. Each characterised acoustic emission was then linked to the microtexture or microtextural interface at that point by matching a post-tribology stitched optical image of the sample with either a pre-tribology petrographic image or an optical image (if the former was unavailable). SEM analysis was used to identify the mechanisms of damage that had occurred with the acoustic emission.

For analysis, the IMDC microtexture was subdivided into (1) IMDC with a low anisotropy quotient (i.e. non-fusible IMDC) and (2) semi-fusible IMDC. Where petrographic images were unavailable, the semi-fusible IMDC were distinguished from non-fusible IMDC based on their appearance and degree of directionality in optical micrographs [23] (semi-fusible IMDC have a greater degree of directionality [41]). Similarly, the RMDC-IMDC interface was subdivided into (1) RMDC-non-fusible IMDC interfaces, and (2) RMDC-semi-fusible IMDC interfaces.

\section{Coke fractography}

As per our previous method [25], each coke lump produced in the two stage small-scale coking process, as well as seven lumps (>50 mm) of the pilot-scale oven coke, were individually dropped from a height of $1 \mathrm{~m}$, onto a stainless steel tray placed on the ground. The coke lump was rotated at each drop to ensure the impact face was varied. Samples were repeatedly dropped until they had fractured into separate pieces of at least $30 \mathrm{~mm}$ in size. Fragments smaller than $30 \mathrm{~mm}$ in size were retained but not analysed. If a coke sample remained unbroken after ten drops, the height was increased to $2 \mathrm{~m}$, and the process repeated. All samples in this study broke at or before this $2 \mathrm{~m}$ drop height. 
The number of drops at each height and the number of pieces above $30 \mathrm{~mm}$ in size were recorded.

\section{Fractographic analysis}

For each coke fractured, the two largest fracture surfaces were analysed. This was performed at two levels of magnification; on a macro and a micro level (see below), adapting our previously reported method [25].

\section{Macro analysis}

High resolution photographs of the fracture faces were recorded under tungsten lights using a Canon EOS60D fitted with an EFS 18 -135 mm Macro lens using a tungsten

filter. The fracture faces were then examined by eye with the aid of a magnifying lamp and photographs. Three parameters for each fracture face were quantified: mean porosity, the size range of IMDC visible and the extent of fracture propagation through the RMDC ('RMDC cracking'). Each of these parameters was quantified only for the fracture faces larger than $5 \mathrm{~mm}$ at the longest dimension.

\section{Micro analysis}

For micro analysis, stereomicrographs were recorded using a Zeiss Stemi 2000-C microscope, with two flexible fibre optic lights used to illuminate the sample. Three unique stereomicrographs were recorded for each fracture face using AxioVision software and a colour video camera. To ensure consistency of results, each image was recorded at $1.6 \times$ magnification, resulting in a field of view of $300 \mathrm{~mm}^{2}$. In each image, a minimum of three IMDC were selected at random. For each IMDC, the following parameters were quantified: size, $\%$ transgranular cracking, $\%$ intergranular cracking, $\%$ interface porosity. 


\section{Quantification of fractography observations}

Table 3 lists the microstructural features used to describe the coke fracture faces. Tables 4 and 5 and Figure 3 show the scales for features quantified using a categorical scale. After the micro analysis, the \% intergranular cracking and \% interface porosity were combined and then inverted to give a value for 'IMDC boundary quality' as a percentage.

In order to compare cokes, standardisation of the data was carried out to show the contribution of each feature to coke mechanical strength on a common 0 to 10 scale. A summary of this process is described below.

Using the data from all the cokes studied at UoN (formed using either a recovery pilot-scale oven or UoN's sole-heated oven), including those from this study, the overall mean $(\mu)$ and standard deviation $(\sigma)$ of the values for each parameter listed in Table 3 were calculated. This was used to convert the mean value of each coke to a $z$-score $(z=$ $\frac{x-\mu}{\sigma}$ where $\mathrm{x}$ is the raw value). This $\mathrm{z}$-score was then converted to a common 0 to 10 scale for each parameter using $(z s c o r e+3) \times\left(\frac{10}{6}\right)$. This enabled the full 0-10 range to cover 3 standard deviations of the overall mean. 


\section{Results and discussion}

\section{Microstructural analysis}

First, the microstructures of the small-scale sole-heated oven (SHO) coke MRLVS and its equivalent pilot oven (PO) coke MRLV were compared using high resolution optical micrographs of samples of each coke. It is important that the coke microstructure is replicated by the SHO since the presence of large pores and a high percentage total porosity can adversely influence coke strength. Figure 4 shows stitched optical micrographs of a polished sample of (a) the SHO coke and (b) the PO coke. Optical image analysis of samples of each coke revealed the mean porosity in the SHO coke to be on average $\sim 2 \%$ higher than its PO analogue (see Table 6). However, given the heterogeneous nature of coke and the standard deviation between the measurements, it was concluded that this difference is insignificant.

Sampling a SHO coke potentially provides a more accurate estimate of the total porosity of a coke compared to sampling a PO coke, since the properties within the coke are more uniform than between lumps of coke sampled from the pilot-scale oven. This is also the likely explanation for the slightly smaller standard deviation between samples for the SHO coke compared to the PO coke (see Table 6).

In addition to the total porosity, it is important to assess the size distribution of the porosity. The pore size distributions for each coke were measured using the area for each pore. The data for each coke is presented in Figure 5 as the percentage of total pores versus the pore area, which was measured in $\mu \mathrm{m}^{2}$. This figure demonstrates that apart from the presence of a small amount of very large pores in the SHO coke MRLVS $\left(>1,000,000 \mu \mathrm{m}^{2}\right)$ and a slightly larger proportion of smaller pores in the PO coke MRLV, the pore size distributions for the two cokes were very similar. This finding differs from that found in a previous study [7] in which a higher proportion of smaller 
pores was found in the SHO cokes compared to their PO analogues. However, in this previous study, different coking conditions were used in the SHO to prepare the cokes. In particular the maximum temperature in the SHO was substantially less than that in the PO analogue. This highlights the importance of replicating coking conditions to reproduce the coke microstructure.

To summarise, the degree of similarity in the pore size distributions for cokes MRLVS and MRLV shows that the small-scale coking protocol adopted in this paper can replicate the microstructure of cokes formed in a pilot-scale oven from single coals.

\section{Microtextural analysis}

Evidence for the similarity in the degree of optical anisotropy between the laboratoryscale SHO coke and the PO coke microtextures was obtained using petrographic imaging (see Figure 6) and microtextural composition analysis (see Table 7). Whilst these measurements initially suggested that there is a slightly higher proportion of fused carbon in the PO coke than in the SHO coke, given the measurement error indicated by our previous analysis of multiple samples of the same coke (not published or shown here), the small area of samples analysed, and the small sample numbers, the differences between the two cokes are not statistically significant. Further, the boundary between the classifications of low and medium bireflectance can be considered to be arbritary, with only small changes in bireflectance necessary to push the material into one classification or the other.

\section{Coefficient of friction analysis}

One of the key measurements that can be obtained from tribological testing is the coefficient of friction (COF) [12]. The frictional force between two opposing surfaces, i.e. the resistance of the two surfaces to relative motion, indicates the susceptibility of a 
test material to tribological wear. A COF of zero indicates a frictionless surface. The COF values obtained from the frictional force measured during tribological testing thus give an indication of the wear properties of the coke [22]: the higher the COF, the greater the potential to transfer mechanical energy to the coke that can weaken or break its surface structure.

The mean COF for the SHO coke MRLVS and the PO coke MRLV showed a similar trend over time (see Figure 7), after accounting for the standard deviation between tests for each coke (see Supplemental Material Table 1). The only difference between the two cokes is the offset between the two curves, whereas typically the shape of the COF curves over time differs for different cokes as a function of their parent coal properties $[11,12]$. This provides evidence for the similarity of the microtextural composition of the two cokes, as was indicated in the coke petrographic composition analysis (see Table 7).

\section{Scratch test analysis}

Progressive loading linear scratch tests were conducted on samples of both cokes. Figure 8 presents a stitched SEM image showing an example of a scratch test performed on PO coke MRLV. The scratch direction is from left to right in Figure 8. The mechanisms of fracture or damage observed within the RMDC as a result of the scratch testing were similar between the SHO and PO cokes, as illustrated by the stacked bar charts shown in Figure 9, in which the mechanisms of damage are grouped by microtexture or microtextural interface and by load range. Load range 1 refers to a 10-40 $\mathrm{N}$ range, load range $240-70 \mathrm{~N}$, and load range $370-100 \mathrm{~N}$. The load range groupings were due to the damage mechanisms varying with the applied loading force. 
Our previous publication [23] grouped the acoustic emissions generated during coke scratch tests into distinct "signatures" based on the corresponding change in the COF that occurred at the acoustic emission maxima. The assigned signature types were found to be related to both the rank of the parent coal and the fracture toughness of the microtexture at the location at which the acoustic emission occurred. There were no significant differences in the distribution of the acoustic emission peak signature types at comparable loading range between the SHO coke MRLVS and the PO coke MRLV (data not shown). This indicates the RMDC fracture toughness and abrasion resistance were relatively similar between the two cokes.

The severity of the damage to the RMDC was slightly higher for SHO coke MRLVS than PO coke MRLV (see Figure 10) but the difference was found not to be statistically significant after applying the one-way analysis of variance (ANOVA) test (results shown in Supplemental Information Figures S1 and S2, which are reproduced from [11]). The ANOVA test was chosen since it is a powerful and widely-used statistical test [42], and allows for the skewed distribution of the damage severity parameter.

\section{Fractographic analysis}

A fractographic approach was applied as a further independent test for any differences in the breakage behaviour of the two cokes. Figure 11 provides an example of an MRLVS fracture face following coke breakage. Key features which may have contributed to the coke failure are labelled, including transgranular and intergranular cracking of an IMDC, fracture propagation through the RMDC, and the agglomeration of pores.

These key features visible on coke fracture faces were quantified, converted to a 0-10 scale based on z-score scaling, and summarised using a radar graph. The radar graph 
was used to visually present the results and facilitate comparison of the two cokes (see Figure 12). In this graph, a '+' sign denotes that the mechanism or feature contributed favourably to coke mechanical strength, a '-' sign denotes an adverse influence on coke mechanical strength, and a ' + -' sign denotes that the contribution could be either positive or negative depending on the influence of other strength-contributing factors in the coke. The 'thick' lines in the graph represent the overall mean and three standard deviations from the mean, whilst the finer lines represent one and two standard deviations from the mean.

Whilst the IMDC boundary quality was found to be higher and the proportion of transgranular cracking of the IMDC lower for the SHO coke compared to the PO coke (see Figure 12), the data were not statistically significantly different. This may be a reflection of the small sample size. Additional parameters, such as the degree of crack propagation through the RMDC, showed little variation and were statistically indistinguishable between the SHO coke and the PO coke.

\section{Discussion on Repeatability of the Results}

Due to the inherent heterogeneous nature of coke, there is known to be measurement error in all of the techniques used in this study. Moreover, the fractographic and scratch test analyses are both subjective, requiring an expert to quantify the mechanisms of fracture or damage. Whilst a database of results for each of the applied techniques has been acquired (see Supplemental Information Figures S1 and S2 for examples), further numbers of each coke type need to be analysed to enable accurate determination of the measurement error for each technique. Nevertheless, use of each of the applied techniques to assess coke strength parameters has been extensively reported 
in the literature, as detailed in the Introduction, highlighting their development and adequacy for assessment of different aspects of coke quality. 


\section{Conclusions}

A coke produced using a custom-built sole-heated oven, and a coke produced in a pilotscale oven from matched coal, were compared using a range of analytical techniques in order to determine whether the laboratory-scale oven can successfully replicate the production of pilot-scale oven cokes.

The following tests were performed on the two cokes: microstructural analysis, microtextural analysis, tribological testing and analysis, scratch testing, and fractographic testing and analysis. In no case was there any statistically significant difference observed between the cokes.

It is important to consider the small differences that do exist in the SHO and PO cokes in the context of the huge difference in the charge size and within charge heterogeneity. The PO coke was sampled from a $400 \mathrm{~kg}$ oven, and the SHO coke from a $350 \mathrm{~g}$ charge size, which highlights the difficulty in obtaining a representative and consistent sample from the PO in comparison with the SHO. Moreover, it is well-known that wall-to-centre variability exists within the PO. In cognizance of these sampling and heterogeneity issues, we have shown in this paper that coke from both a $400 \mathrm{~kg}$ PO and a $350 \mathrm{~g}$ SHO are demonstrably similar in microstructure, microtexture, abrasion resistance and breakage behaviour.

We can conclude that our propriety SHO, used in combination with an annealing step in a muffle oven, can provide guidelines as to the expected behaviour of coke produced in the recovery pilot-scale coke oven. Better control over the temperature profile within the SHO oven may reduce any slight deviations from the properties of comparable cokes formed in pilot-scale ovens. The bench-scale oven is clearly a cost- 
effective method for providing guidelines on coke quality and for screening a coke for particular attributes, such as strength-contributing factors.

\section{Acknowledgements}

We gratefully acknowledge ACARP (project C25043) for financial support and the coal company that supplied the coal and pilot oven coke samples. We thank Pearson Coal Petrography for the analysis of coke microtexture, Leanne Matthews (UoN) for assistance with sample preparation, Kim Colyvas (UoN) for assistance with statistical analysis, and the Electron Microscope and X-ray Unit (UoN) for SEM access, with a particular thank you to Yun Lin.

\section{Declaration of interest statement}

No potential conflict of interest was reported by the authors.

\section{Funding}

We gratefully acknowledge ACARP (project C25043) for funding this research work. 


\section{References}

[1] T. MacPhee, L. Giroux, K.W. Ng, T. Todoschuk, M. Conejeros, C. Kolijn, A Facile Approach to the CSR Determination of Metallurgical Coke, 8th International

Metallurgical Trade Fair with Congresses, Dusseldorf, Germany. 25-29 June. 8 pages., 2011.

[2] T. MacPhee, L. Giroux, K.W. Ng, T. Todoschuk, M. Conejeros, C. Kolijn, Small Scale Determination of Metallurgical Coke CSR, 13th International Conference on Coal Science and Technology, Oviedo, Spain. 9-13 October. 10 pages., 2011.

[3] T. MacPhee, L. Giroux, K.W. Ng, T. Todoschuk, M. Conejeros, C. Kolijn, Small scale determination of metallurgical coke CSR, Fuel 114 (2013) 229-234.

[4] P. Bennett, M. Wimalaratne, L. Johnson, J. Bottle, Implications of Coking Conditions on CSR. ACARP Project C22039 Final Report, 2015.

[5] S. Lee, Y. Hui, M. Mahoney, J. Yu, An In-situ Study of the Plastic Layer Formation in Coking Coals using a Lab Scale Test Furnace. ACARP Project C24054 Final Report, 2018.

[6] M. Mahoney, N. Andriopoulos, J. Keating, C.E. Loo, S. McGuire, Pilot scale simulation of cokemaking in integrated steelworks, Ironmaking and Steelmaking 32(6) (2005) 468-478.

[7] K. Steel, R. Dawson, D. Jenkins, R. Pearce, M. Mahoney, H. Lomas, R. Roest, H. Rogers, Links Between Microstructure Development in Softening Coal and the Characteristics Controlling Coke Quality. ACARP Project C23048 Final Report, 2015.

[8] M. Mahoney, D.R. Jenkins, R. Pearce, K. Steel, R. Roest, H. Lomas, S. Mayo, Development Of Coke Microstructure by 3D Imaging of Quenched Semicoke-Plastic Layer-Coal Beds, ICCS\&T/ACSE Conference 27 Sept - 01 Oct 2015, Melbourne, Australia, 2015.

[9] M. Mahoney, R. Roest, H. Lomas, R. Fetscher, D.R. Jenkins, R. Pearce, S. Mayo, Examination of coke formation through microstructure of sole-heated oven tests, 9th International Metallurgical Technology Trade Fair with Congresses and 2nd European Steel Technology and Application Days (METEC-ESTAD), 15-19 June 2015, Dusseldorf, Germany, 2015.

[10] M. Mahoney, D. Jenkins, K. Steel, Mechanistic Model for the Understanding of Sole Heated Ovens. ACARP Project C23047 Final Report, 2016.

[11] H. Lomas, R. Roest, M.R. Mahoney, A. Wells, R. Stuart, R. Sakurovs, Z. Jiang, H. $\mathrm{Wu}$, The Strength of Interfaces in Metallurgical Coke and its Influence on Coke Abrasion. ACARP Project C25043 Final Report, 2017.

[12] H. Lomas, R. Roest, T. Thorley, A. Wells, H. Wu, Z. Jiang, R. Sakurovs, S. Wotherspoon, R.A. Pearson, M.R. Mahoney, Tribological Testing of Metallurgical Coke: Coefficient of Friction and Relation to Coal Properties, Energy and Fuels 32 (2018) 12021-12029.

[13] A.S. Jayasekara, B.J. Monaghan, R.J. Longbottom, M.R. Mahoney, K. Hockings, The study of the $\mathrm{Ca}$ dispersion in coke and effect of $\mathrm{Ca}$ and $\mathrm{Fe}$ on the coke reactivity using the sole heated oven cokes, Fuel 264 (2020) 116818.

[14] S. Lee, J. Yu, M. Mahoney, A. Tahmasebi, R. Stanger, T. Wall, J. Lucas, In-situ study of plastic layers during coking of six Australian coking coals using a lab-scale coke oven, Fuel Processing Technology 188 (2019) 51-59.

[15] S. Lee, M. Mahoney, J. Yu, Advances in the understanding of the formation and chemistry of the plastic layer during coke-making: A comprehensive review, Fuel 263 (2020) 116655. 
[16] L. Johnson, P. Bennett, S. Grimish, Quality of Stamp Charged Cokes and

Stampability of Coals at Small Scale. ACARP Project C22035 Final Report, 2014.

[17] M.S. Nyathi, R. Kruse, M. Mastalerz, D.L. Bish, Impact of Oven Bulk Density and Coking Rate on Stamp-Charged Metallurgical Coke Structural Properties, Energy and Fuels 27 (2013) 7876-7884.

[18] M.S. Nyathi, R. Kruse, M. Mastalerz, D.L. Bish, Investigation of Coke Quality Variation between Heat-Recovery and Byproduct Cokemaking Technology, Energy and Fuels 31 (2017) 2087-2094.

[19] L. North, K. Blackmore, K. Nesbitt, M.R. Mahoney, Models of coke quality prediction and the relationships to input variables: A review, Fuel 219 (2018) 446-466.

[20] R. Roest, H. Lomas, K. Hockings, M.R. Mahoney, Tribological Approach to Investigate the Interface Properties in Metallurgical Coke, Energy and Fuels 31(2) (2017) 1422-1428.

[21] H. Lomas, R. Roest, S. Gupta, R.A. Pearson, R. Fetscher, D.R. Jenkins, R. Pearce, R. Kanniala, M.R. Mahoney, Petrographic Analysis and Characterisation of a Blast Furnace Coke and its Wear Mechanisms, Fuel 200 (2017) 89-99.

[22] B. Bhushan, Introduction to Tribology, Second Edition ed., Wiley, New York, 2013.

[23] H. Lomas, R. Roest, A. Wells, H. Wu, Z. Jiang, R. Sakurovs, R. Stuart, L. North, T. Thorley, M.R. Mahoney, Estimating Coke Fracture Toughness using Acoustic Emissions and Changes in Coefficient of Friction during Scratch Testing, Fuel 226 (2018) 564-572.

[24] G.D. Quinn, Fractography of Ceramics and Glasses, National Institute of Standards and Technology Recommended Practice Guide - Special Publication 960-16, Washington, DC, USA, 2007.

[25] R. Roest, H. Lomas, K. Hockings, M.R. Mahoney, Fractographic Approach to Metallurgical Coke Failure Analysis. Part 1: Cokes of Single Coal Origin, Fuel 180 (2016) 785-793.

[26] R. Roest, H. Lomas, M.R. Mahoney, Fractographic Approach to Metallurgical Coke Failure Analysis. Part 2: Cokes from Binary Coal Blends, Fuel 180 (2016 ) 794-802.

[27] R. Roest, H. Lomas, S. Gupta, R. Kanniala, M.R. Mahoney, Fractographic Approach to Metallurgical Coke Failure Analysis. Part 3: Characterisation of Fracture Mechanisms in a Blast Furnace Coke, Fuel 180 (2016) 803-812.

[28] R. Roest, H. Lomas, M.R. Mahoney, A Fractographic Approach to Understanding the Mechanisms of Coke Breakage. ACARP Project C22036 Final Report, 2014. [29] X. Xing, H. Rogers, G. Zhang, K. Hockings, P. Zulli, O. Ostrovski, Changes in Pore Structure of Metallurgical Cokes under Blast Furnace Conditions, Energy and Fuels 30 (2016) 161-170.

[30] M. Mahoney, G. O'Brien, P. Hapugoda, K. Warren, D. Riley, L. Lu, Understanding Coal Grain Effects on Coke Quality. ACARP Project C20008 Final Report, 2013.

[31] X. Xing, Pore Structure and Integrity of a Bio-Coke under Simulated Blast Furnace Conditions, Energy and Fuels 33 (2019) 2133-2141.

[32] D.E. Pearson, R.A. Pearson, H.-K. Park, Y. Jiao, Quality and Classification of Metallurgical Coke, 7th International Conference on the Science and Technology of Ironmaking, AISTech, Cleveland, Ohio, USA, 4-7 May 2015, 2015, pp. 103-110. [33] H. Lomas, R. Roest, H. Wu, Z. Jiang, R. Sakurovs, A. Anderson, A. Edwards, T. Hill, M.R. Mahoney, P. Koshy, Influence of Elevated Temperature and Gas Atmosphere on Abrasion and Interface Properties in Blast Furnace and Pilot Oven Cokes. ACARP Project C27017 Final Report, 2020. 
[34] T. Kanai, Y. Yamazaki, X. Zhang, A. Uchida, Y. Saito, M. Shoji, H. Aoki, S. Nomura, Y. Kubota, H.H.S. Miyashita, Quantification of the Existence Ratio of NonAdhesion Grain Boundaries and Factors Governing the Strength of Coke Containing Low-Quality Coal, J. Thermal Sci. Tech. 7 (2012) 351-363.

[35] C. Barriocanal, S. Hanson, J.W. Patrick, A. Walker, The characterization of interfaces between textural components in metallurgical cokes, Fuel 73(12) (1994) 1842-1847.

[36] K. Warren, G. O'Brien, G. Krahenbuhl, P. Hapugoda, M.R. Mahoney, R. Pearson, Determining fusibility of inertinite by comparison of matched coal and coke surfaces using imaging analysis methods, 9th International Metallurgical Technology Trade Fair with Congresses and 2nd European Steel Technology and Application Days (METECESTAD), 15-19 June 2015, Dusseldorf, Germany, 2015.

[37] H. Lomas, D.R. Jenkins, M.R. Mahoney, R. Pearce, R. Roest, K. Steel, S. Mayo, Examining Mechanisms of Metallurgical Coke Fracture Using Micro-CT Imaging and Analysis, Fuel Processing Technology 155 (2017) 183-190.

[38] S. Mayo, R. Sakurovs, D. Jenkins, M. Mahoney, Imaging Gas Penetration Inside Coals and Cokes and Determining Influence on Coke Reactivity. ACARP Project C27056 Final Report, 2019.

[39] D. Pearson, R. Pearson, M. Mahoney, O. Scholes, Application of Automated Petrography to Characterize Coke Quality Distribution in Slot-Oven and Non-Recovery Oven Coke, 6th International Conference on Science and Technology of Ironmaking and 42nd Ironmaking Seminar, Rio de Janeiro, Brazil, 2012.

[40] P.R. Pearson DE, Park H-K, Jiao Y., Quality and Classification of Metallurgical Coke., 7th International Conference on the Science and Technology of Ironmaking., ASITech, Cleveland, Ohio, USA, 2015.

[41] K. Benfell, Personal communication from Dr Katharine Benfell, Conjoint Fellow, University of Newcastle.

[42] D.C. Montgomery, Design and Analysis of Experiments (5th ed.), Wiley, New York, 2001. 


\section{Supplemental Material}

Table S1. Standard deviation for the COF between tribological tests for small-scale coke MRLVS and pilot-scale coke MRLV.

\begin{tabular}{llllllll}
\hline \multirow{2}{*}{ Coke } & \multicolumn{8}{l}{ Standard deviation between tests for the COF as a function of time (s) } \\
\cline { 2 - 8 } & $\mathbf{1}$ revolution & $\mathbf{3 0}$ & $\mathbf{6 0}$ & $\mathbf{1 2 0}$ & $\mathbf{1 8 0}$ & $\mathbf{2 4 0}$ & $\mathbf{3 0 0}$ \\
\hline MRLVS & 0.04 & 0.01 & 0.01 & 0.01 & 0.01 & 0.01 & 0.01 \\
MRLV & 0.06 & 0.05 & 0.05 & 0.05 & 0.05 & 0.05 & 0.05 \\
\hline
\end{tabular}


(a)

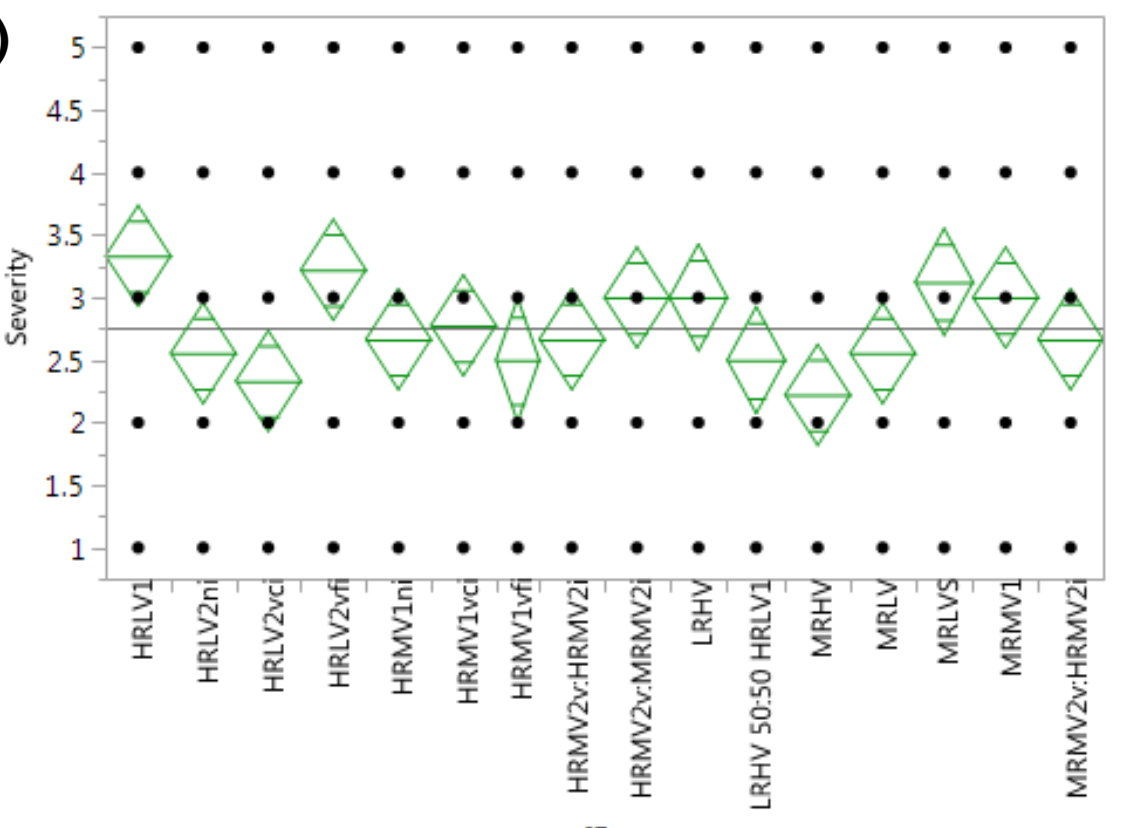

ID

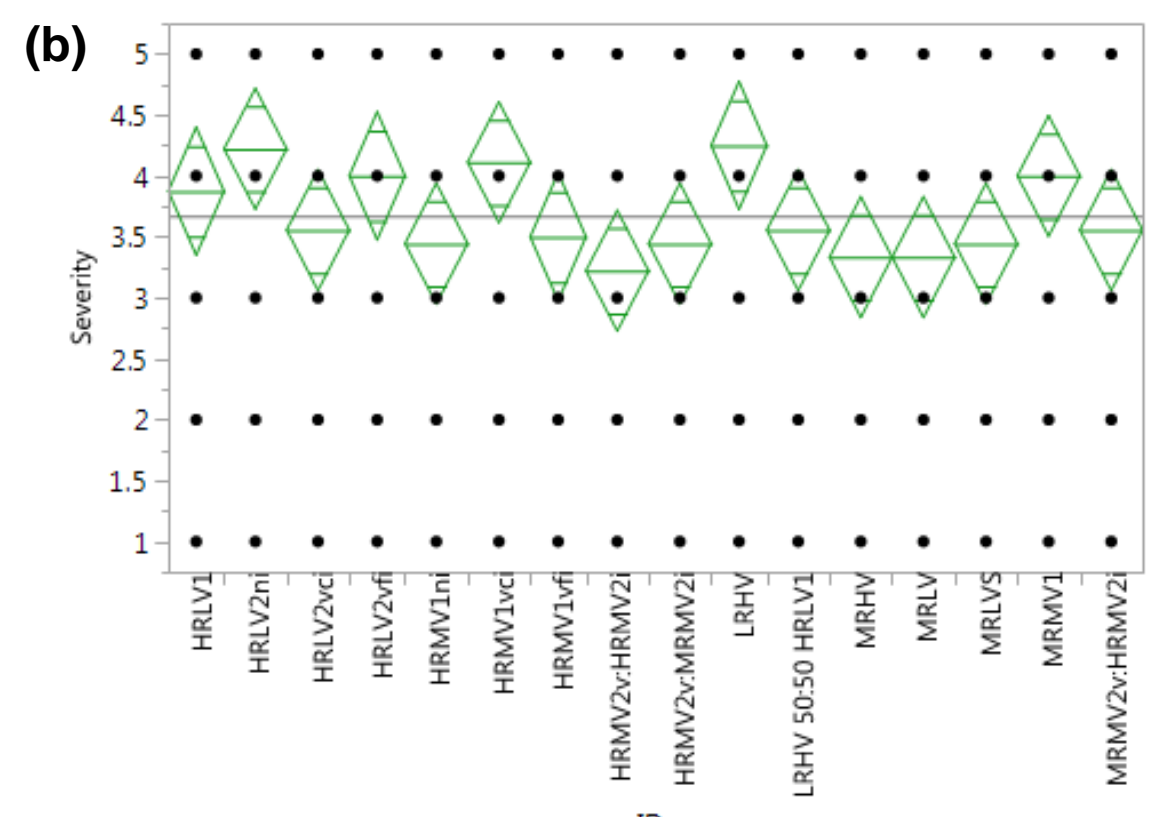

ID

Figure S1. Plots of damage severity against coke code ("ID") for sixteen coke types, generated by one-way analysis of variance (ANOVA) of the damage severity to the RMDC during scratch tests at (a) loading range 1 and (b) loading range 2 . The plots indicate more severe damage to the RMDC in samples of coke MRLVS than MRLV at these two loading ranges (which correspond to (a) 10-40 N and (b) 40-70 N). However, the plots show that the differences were not statistically significant.

The distribution for each coke is indicated by the green diamonds. The central bar in each diamond shows the mean for that coke and the upper and lower bars the $95 \%$ confidence intervals. 


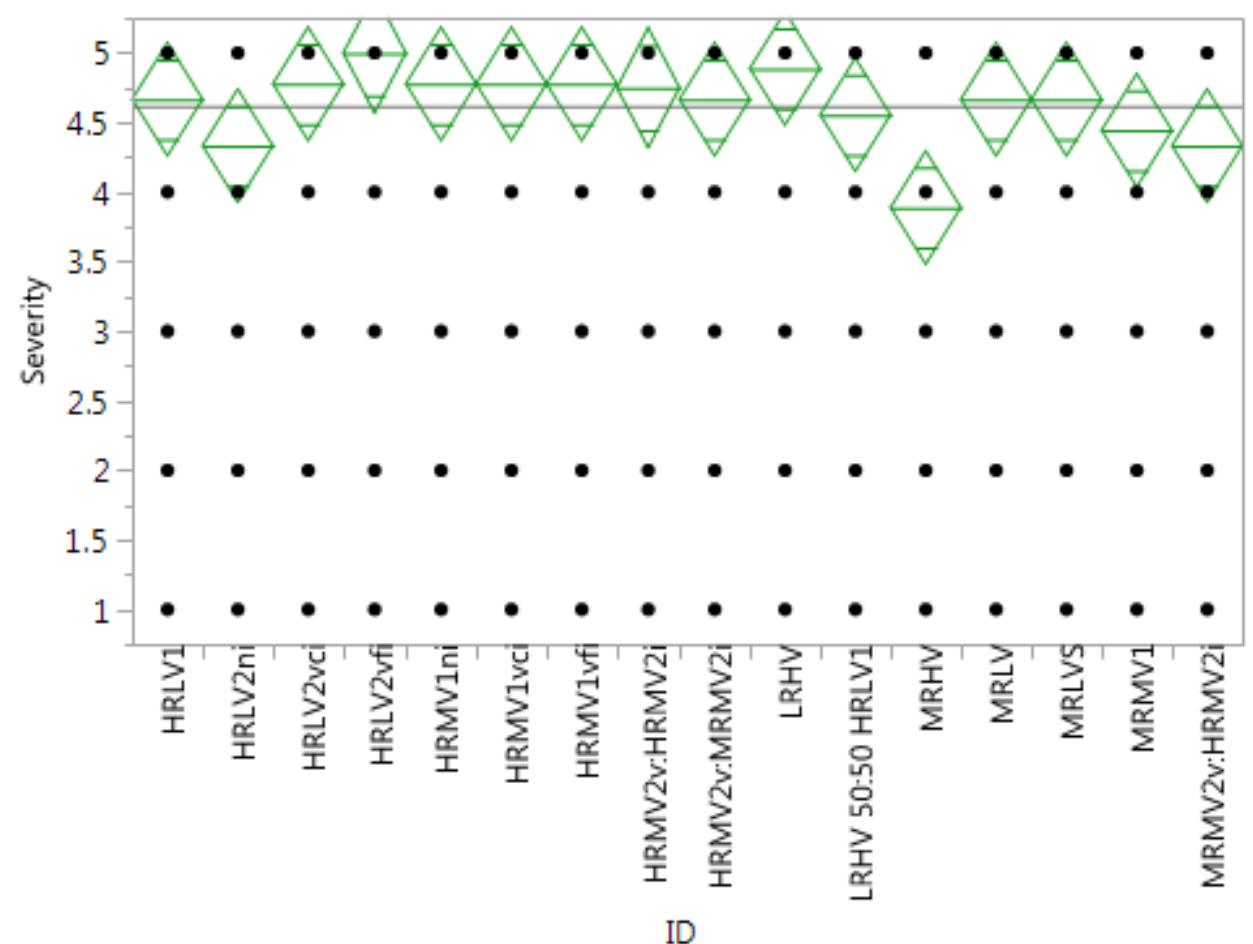

Figure S2. Plot of damage severity against coke code ("ID”) for sixteen coke types, generated by one-way analysis of variance (ANOVA) of the damage severity to the RMDC during scratch tests at loading range 3 (70-100 N). The results for MRLV and MRLVS were almost identical.

The distribution for each coke is indicated by the green diamonds. The central bar in each diamond shows the mean for that coke and the upper and lower bars the $95 \%$ confidence intervals. 


\section{Tables}

Table 1. Properties of the coal used to make the cokes in this study (maceral analysis on an including mineral matter basis), and strength indices for the pilot oven coke.

\begin{tabular}{cccc}
\hline \multicolumn{2}{c}{ Coal properties } & Pilot-scale coke strength indices \\
\hline $\begin{array}{c}\text { Vitrinite content } \\
(\%)\end{array}$ & $\begin{array}{c}\text { Mean max vitrinite } \\
\text { reflectance (\%) }\end{array}$ & ASTM stability & ASTM hardness \\
\hline 44.3 & 1.23 & 59.2 & 66.0 \\
\hline
\end{tabular}


Table 2. Coking conditions for the two compartment charge for formation of the recovery pilot-scale oven coke.

\section{Coking parameter Range/Value}

Coal grind

$\sim 85 \%$ passing $3.35 \mathrm{~mm}$

Charge moisture

$5 \%$

Oven bulk density

$\sim 830 \mathrm{~kg} \mathrm{~m}^{-3}(\mathrm{db})$

Coking time

19.7 hours

Wall temperature

Initially $770^{\circ} \mathrm{C}$ then ramped to $\sim 1050^{\circ} \mathrm{C}$

Final coke temperature at oven centre

$\sim 1030$ to $1060^{\circ} \mathrm{C}$ 
Table 3. Microstructural features and mechanisms of failure identified in fractured coke surfaces. N.B. (+) denotes the parameter contributes positively to coke mechanical strength, (+ -) denotes either a strength or a weakness (but more likely a strength), and (-) denotes a weakness in terms of coke mechanical strength.

\section{Fractographic}

\section{Description}

parameter

IMDC size range The size of the IMDC, quantified as one of three categories (see $(+-) \quad$ Table 4).

Total contact (through physical interaction or chemical bonding)

IMDC boundary between selected IMDC and the surrounding RMDC. This contact quality $(+) \quad$ is reduced by porosity at the interface and intergranular cracking i.e. cracks which run around the IMDC boundary.

Transgranular

cracking Crack cleavage through the IMDC.

(IMDC) (+-)

Mosaic (RMDC) Recorded in six categories, which account for the width as well as cracking (+ -) length of the cracks present in the RMDC (see Figure 4).

Porosity Quantified as one of four categories, as a percentage area of the (RMDC) (-) $\quad$ total fracture face analysed (see Table 5). 
Table 4. Initial scale used to quantify IMDC size range.

\begin{tabular}{ll} 
IMDC size range & Scale \\
\hline $0-1.5 \mathrm{~mm}$ & 1 \\
$0-5.0 \mathrm{~mm}$ & 2 \\
$0-10.0 \mathrm{~mm}$ & 3 \\
\hline
\end{tabular}


Table 5. Initial scale used to quantify RMDC porosity.

Porosity (RMDC) Scale

$0-25 \%$ of fracture face $\quad 1$

$25-50 \%$ of fracture face 2

$50-75 \%$ of fracture face 3

$75-100 \%$ of fracture face $\quad 4$ 
Table 6. Total porosity for SHO coke MRLVS and PO coke MRLV, measured using optical micrographs of samples of each coke.

\begin{tabular}{|c|c|c|}
\hline \multirow{2}{*}{ Sample } & \multicolumn{2}{|c|}{ Porosity (\%) } \\
\hline & MRLVS & MRLV \\
\hline 1 & 52.3 & 46.8 \\
\hline 2 & 48.5 & 51.7 \\
\hline 3 & 49.2 & 44.7 \\
\hline Mean & $\mathbf{5 0 . 0}$ & 47.7 \\
\hline Standard deviation & 2.0 & 3.6 \\
\hline
\end{tabular}


Table 7. Petrographic composition analysis for SHO coke MRLVS and PO coke MRLV, analysed by Pearson Coal Petrography Inc.

\begin{tabular}{lll}
\hline & Volume (\%) & \\
\cline { 2 - 3 } Coke component & MRLVS & MRLV \\
\hline Low reflective inert (isotropic) & 31.43 & 28.99 \\
High reflective inert (isotropic) & 0.18 & 0.19 \\
Pyrolytic carbon (uniaxial positive) & 0 & 0 \\
Fused inertinite (uniaxial negative) & 0.30 & 0.47 \\
Spherylytic carbon & & 0 \\
Low bireflectance (circular form) & 44.31 & 27.92 \\
\hline High bireflectance (ribbon form) & 1.54 & 2.50 \\
\hline
\end{tabular}




\section{Figures}
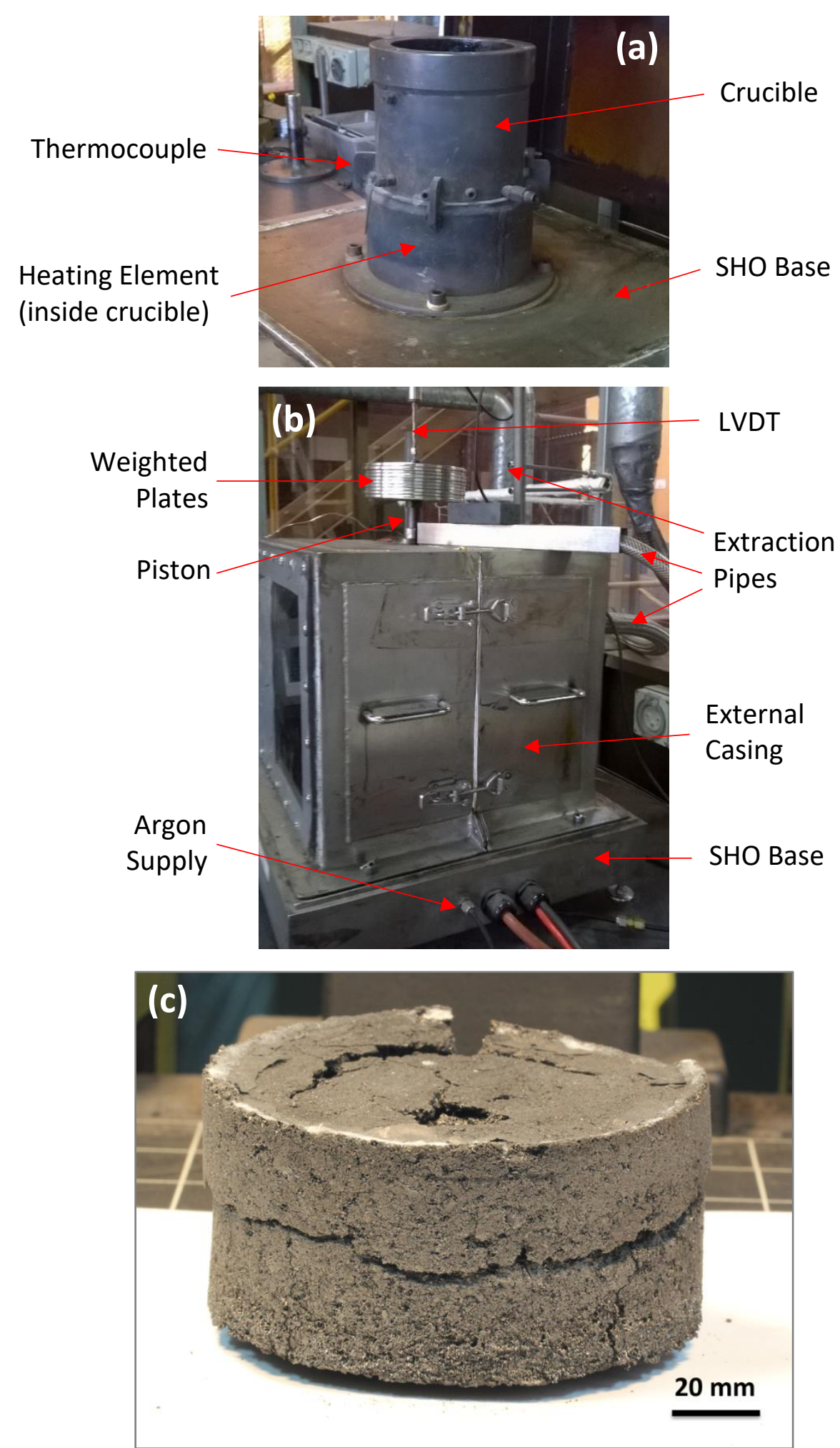

Figure 1. 


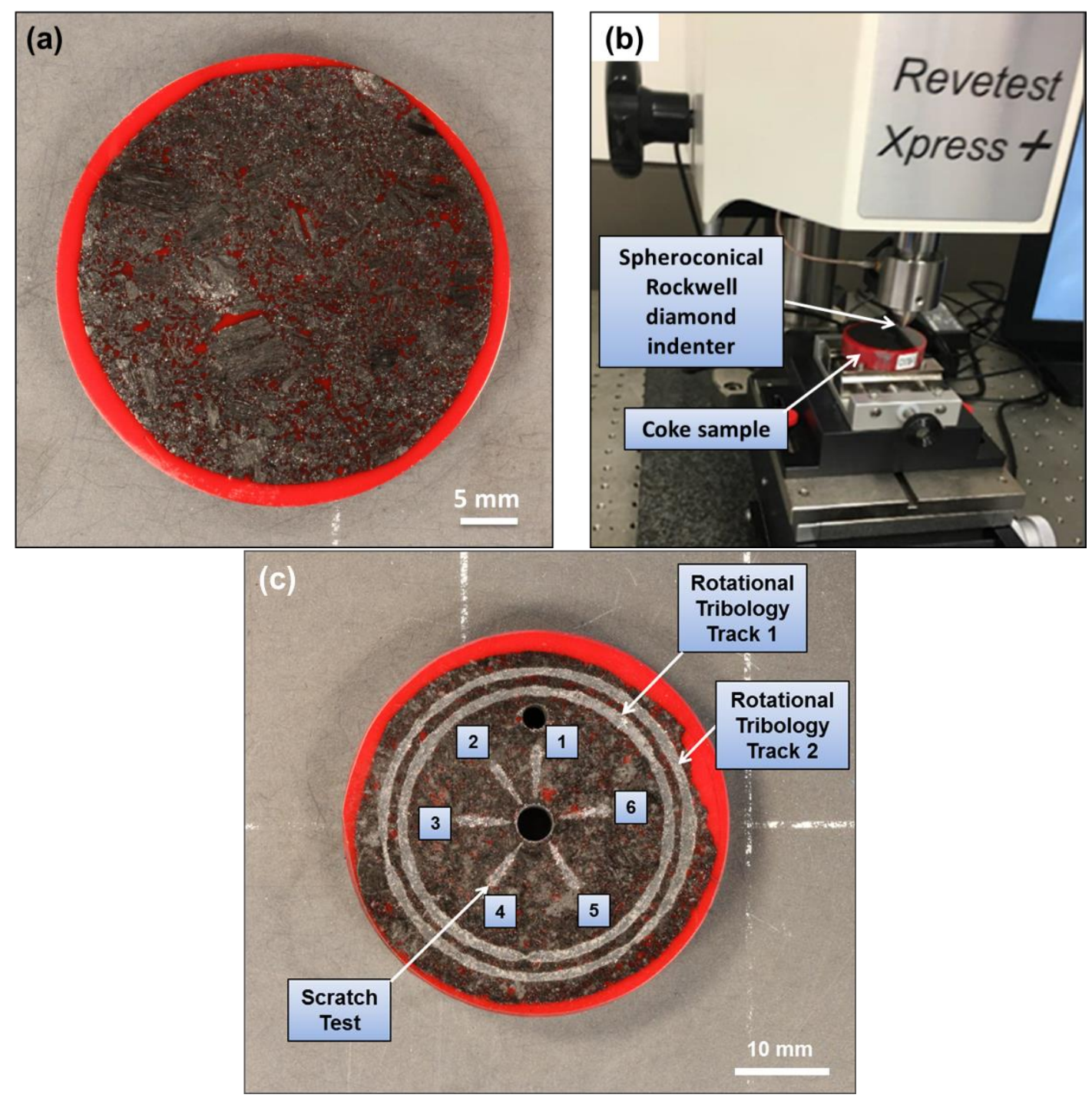

Figure 2. 


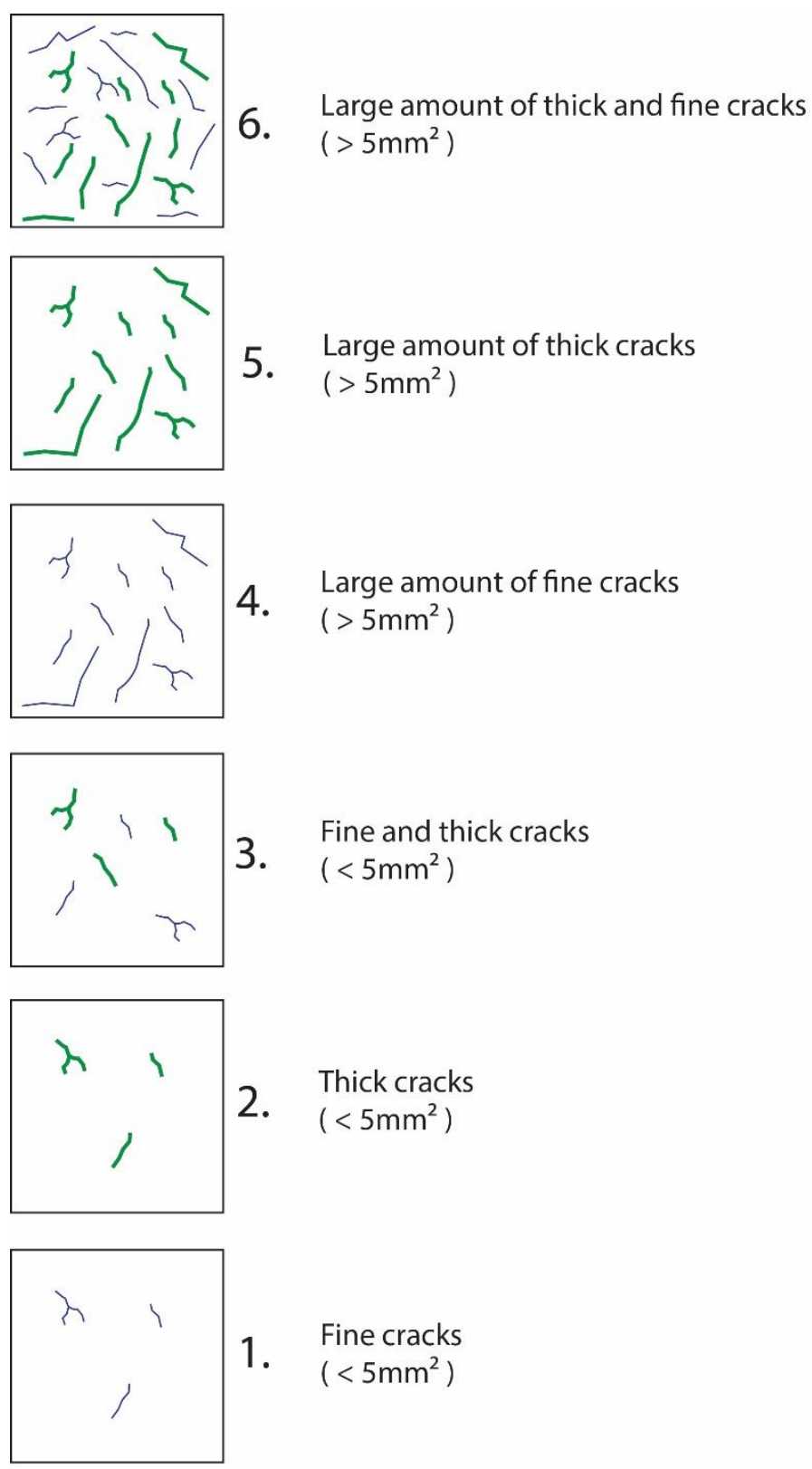

Figure 3. 

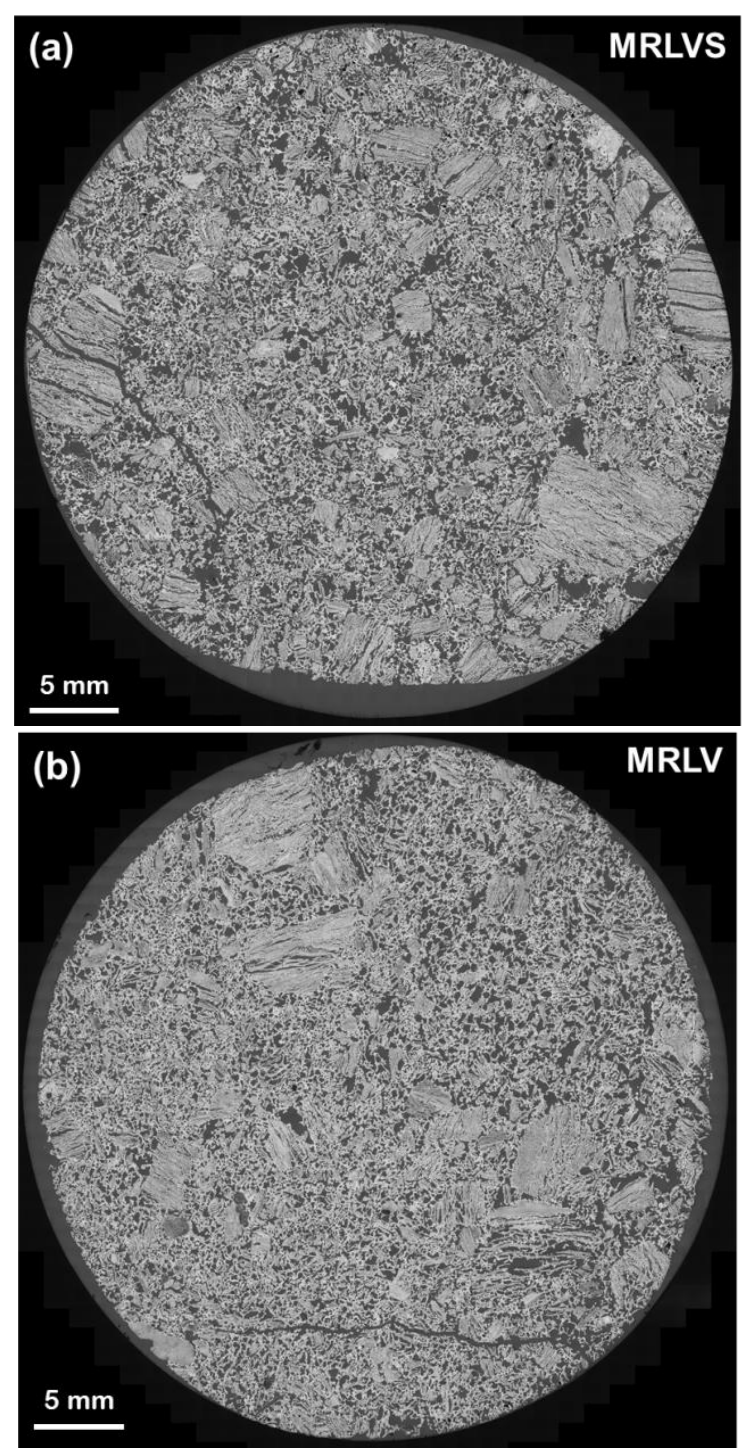

Figure 4. 


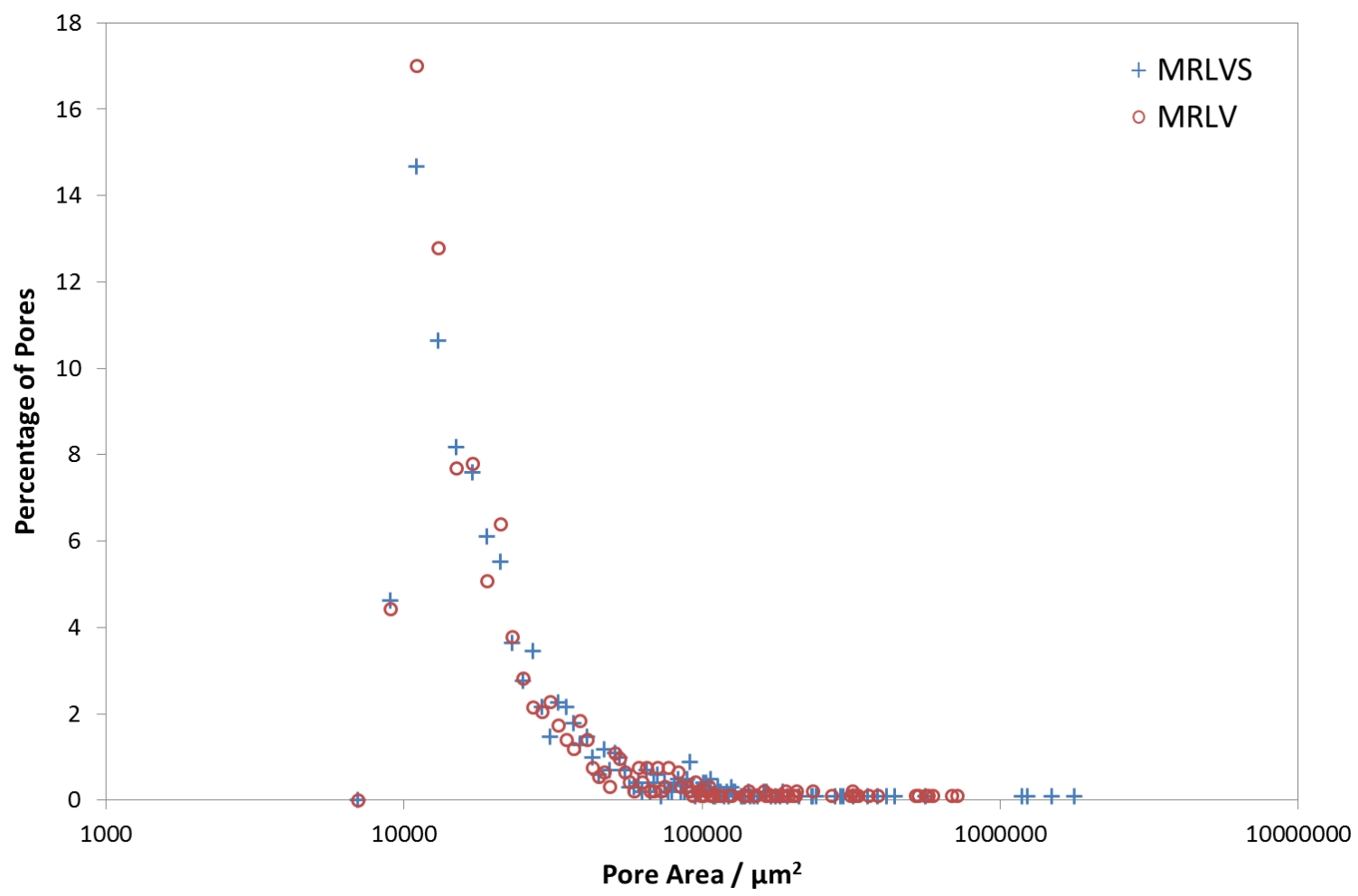

Figure 5. 


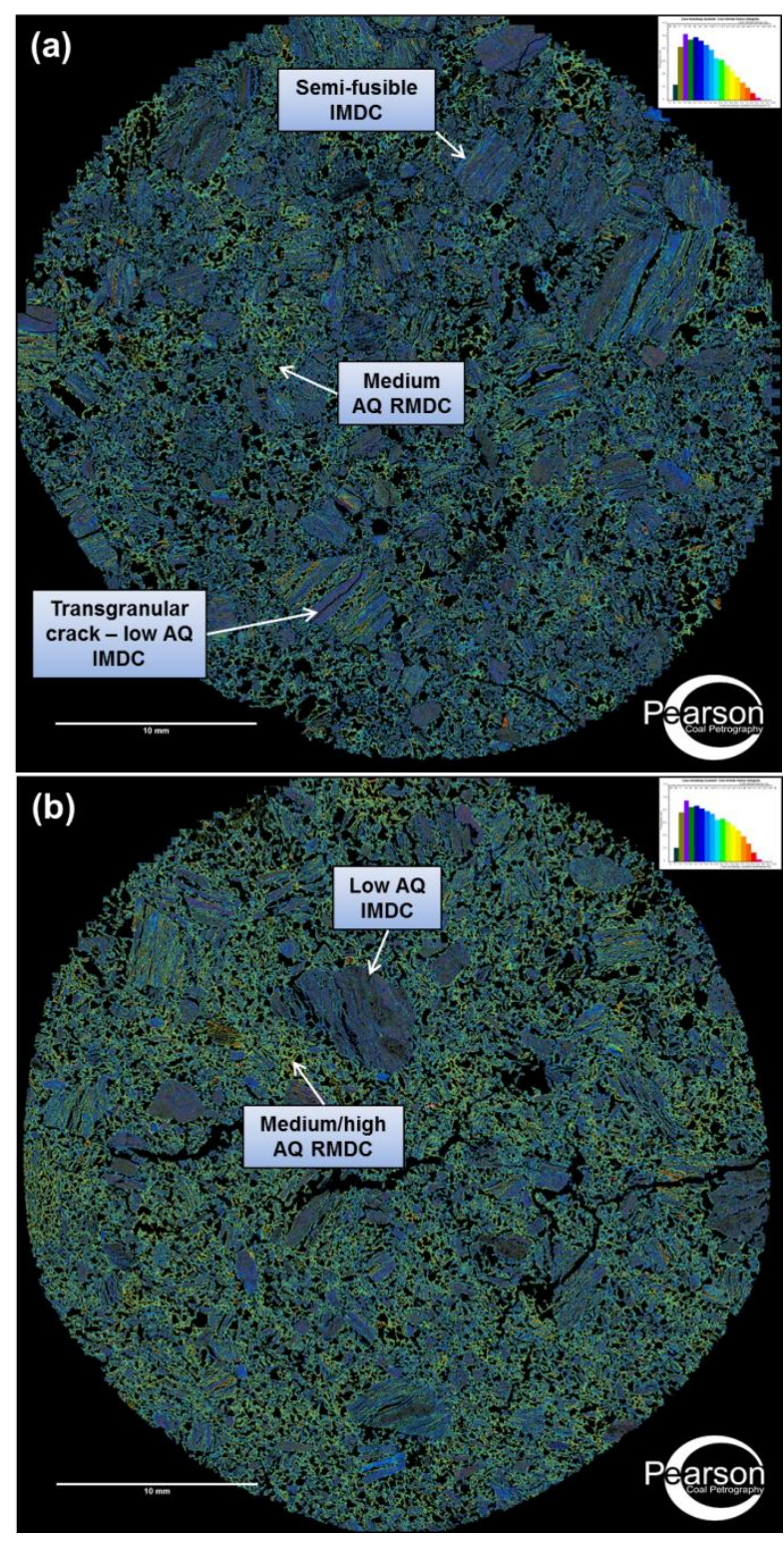

Figure 6. 


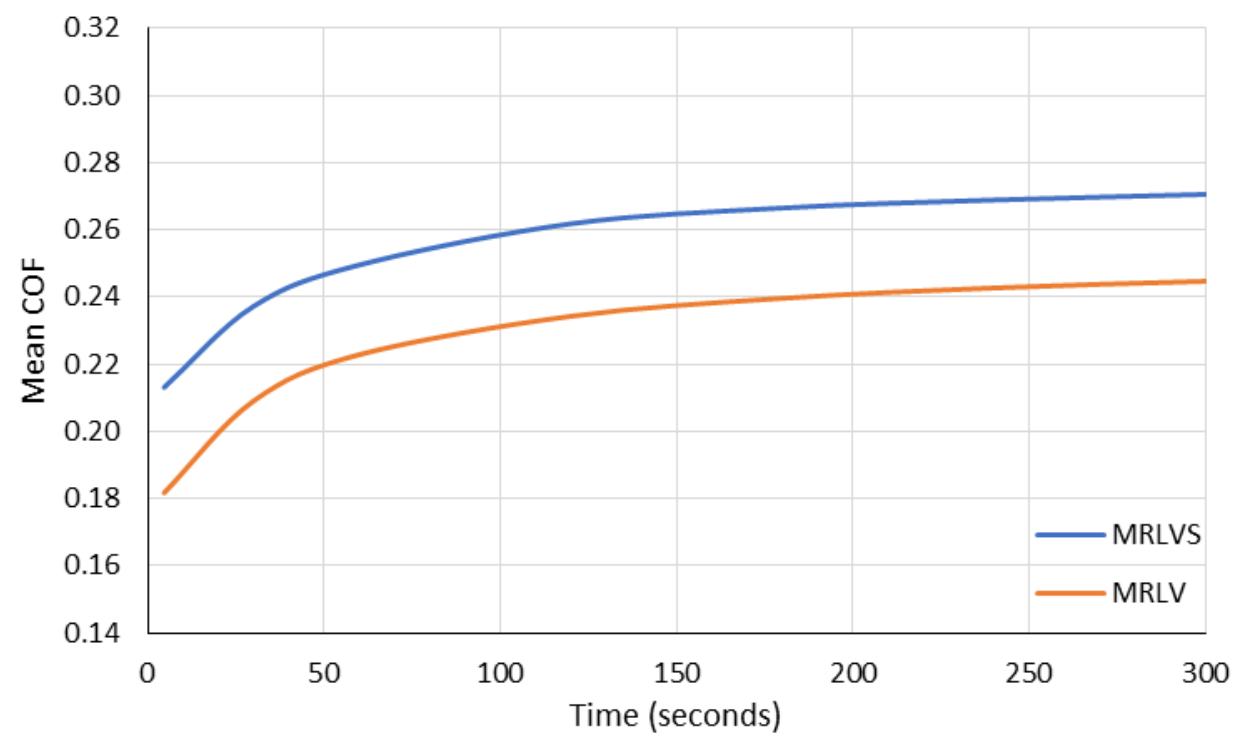

Figure 7. 


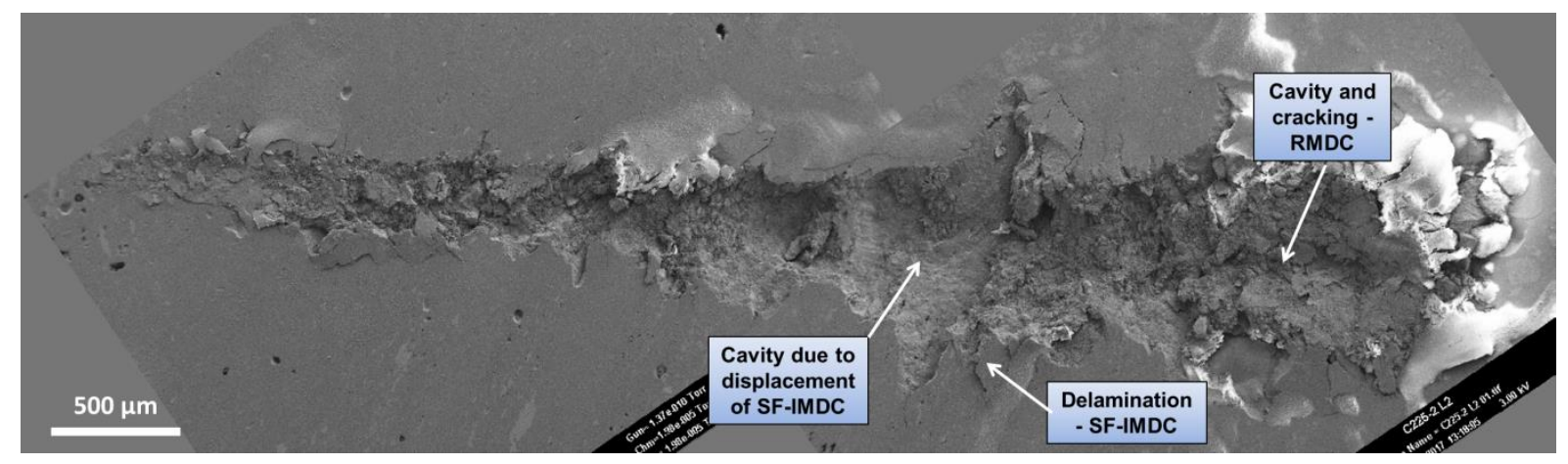

Figure 8. 
(a)

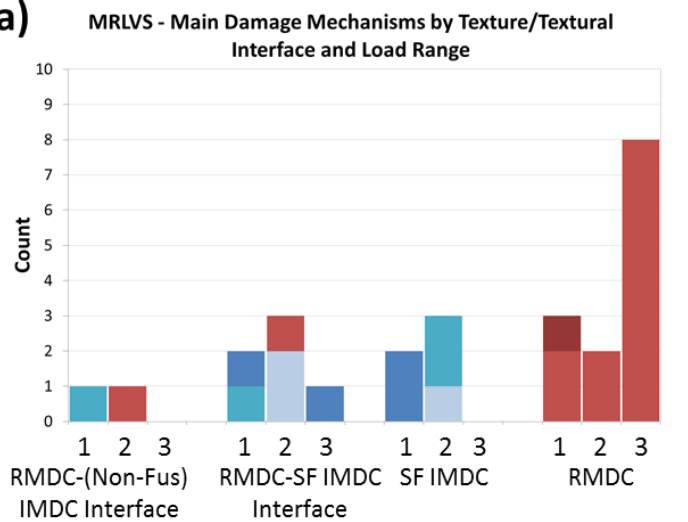

(b) MRLV - Main Damage Mechanisms by Texture/Textural

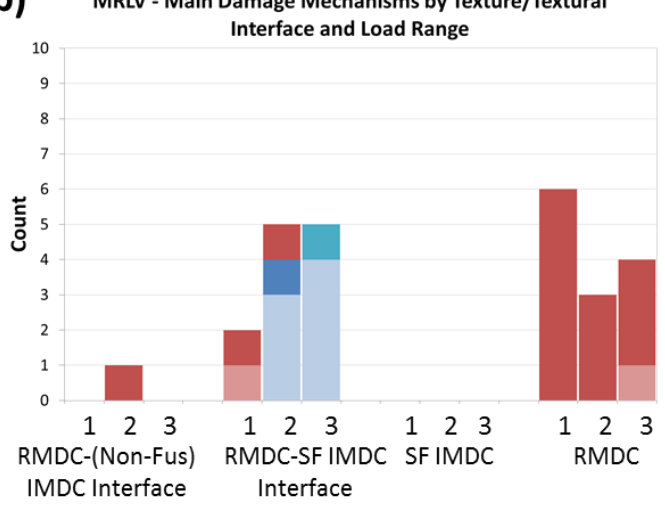

Legend for Main Damage Mechanisms

Displacement - IMDC

= IgC - IMDC

- TgC, Delam, CGAP or IgC \& TgC - IMDC

- Cavity \& Crack Growth - SF IMDC \& RMDC

- Cavity - RMDC

- Cavity \&/or Crack Growth - RMDC

- Crack Growth - RMDC-Resin Interface

Cavity \&/or Crack Growth - Resin

No or Minimal Damage

\section{Figure 9.}


(a)

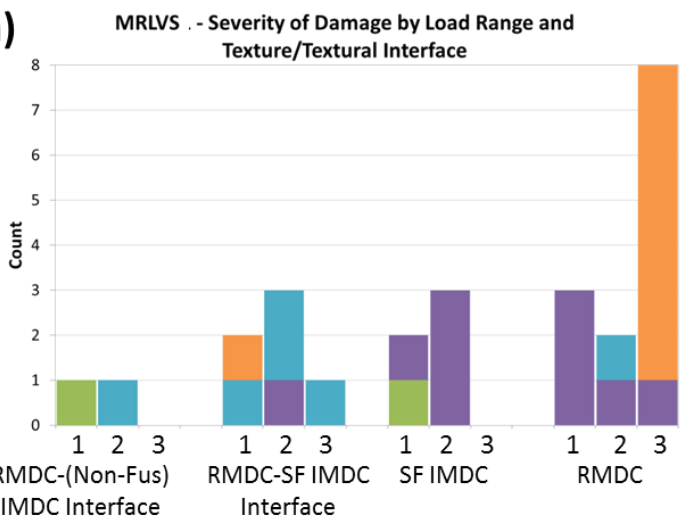

(b) MRLV - Severity of Damage by Load Range and

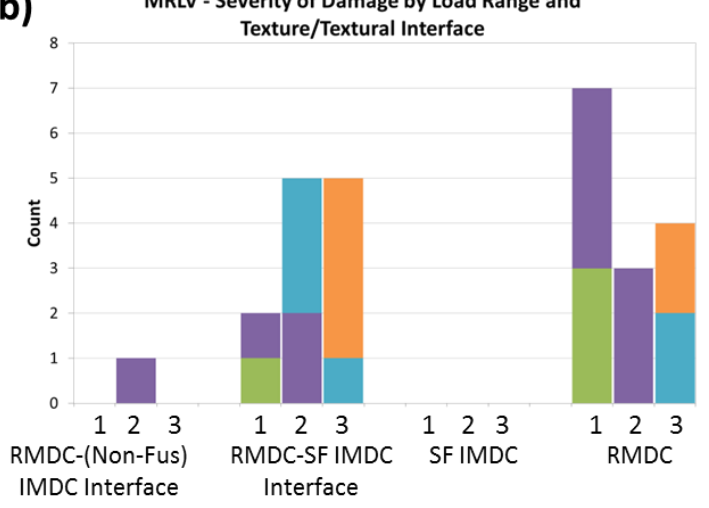

\begin{tabular}{|c|c|}
\hline \multicolumn{2}{|c|}{ Legend for Damage Severity } \\
\hline $\mathbf{1} 1$ & \\
\hline 2 & \\
\hline$=3$ & \\
\hline$=4$ & \\
\hline 5 & \\
\hline
\end{tabular}

Figure 10. 


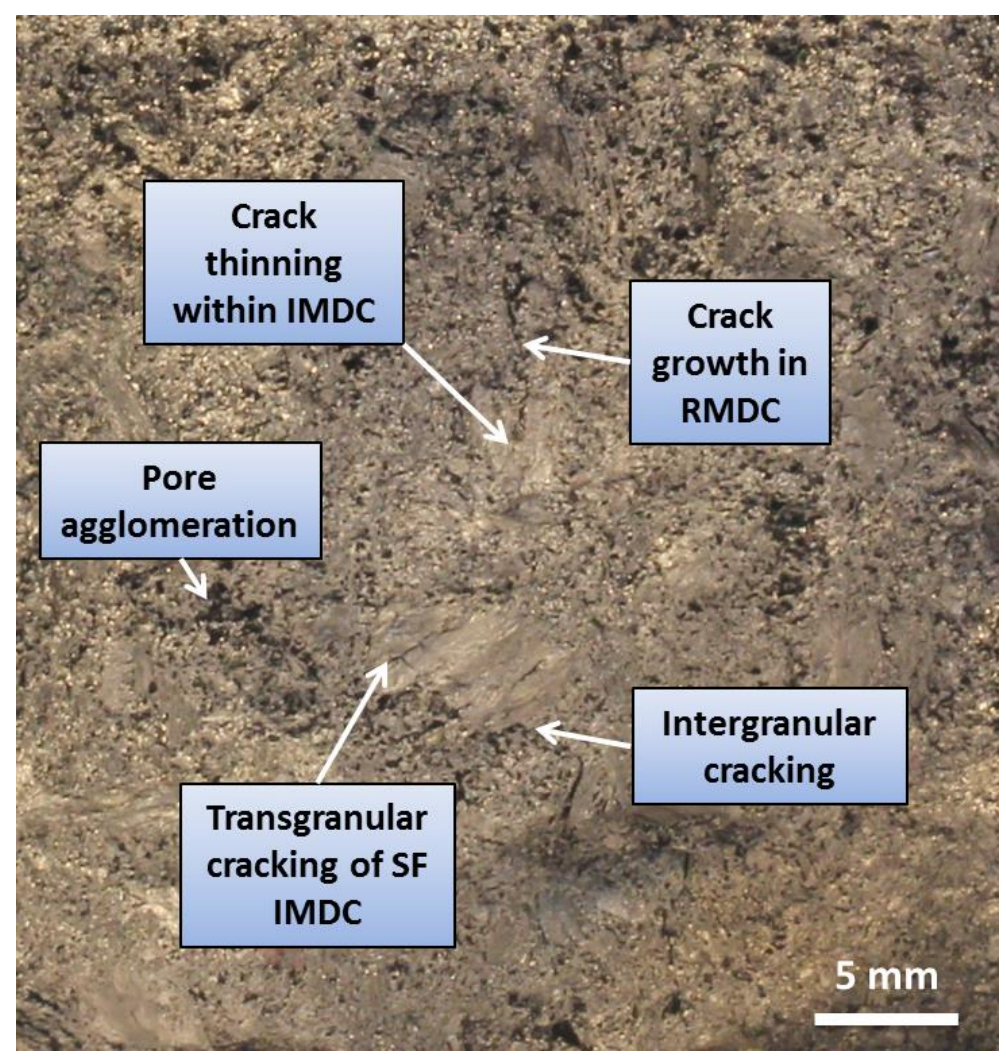

Figure 11. 


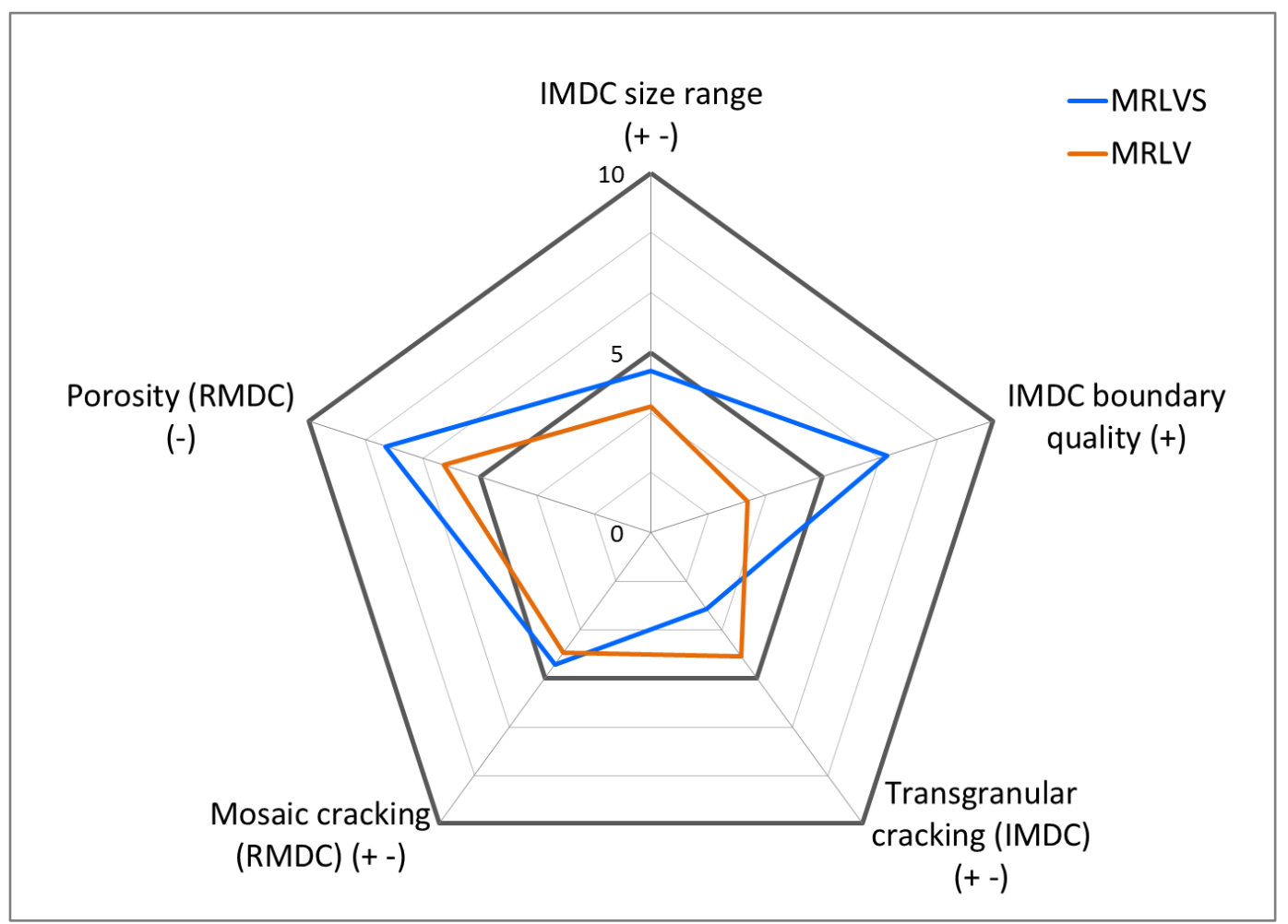

Figure 12. 


\section{Figure captions}

Figure 1. (a) Sole-heated oven internal view. (b) Sole-heated oven external view. (c) Photograph of coke MRLVS produced in the sole-heated oven followed by annealing to $1000^{\circ} \mathrm{C}$.

Figure 2. (a) Photograph of an example polished block of coke MRLV prior to testing. (b) Photograph of the Revetest Xpress Plus scratch tester, with a coke sample ready for testing and the Rockwell diamond indenter labelled. (c) Coke sample post rotational tribology and linear scratch testing. The numbers refer to the six scratch tests which were conducted on this sample.

Figure 3. Initial scale used to quantify mosaic (RMDC) cracking.

Figure 4. Optical micrographs of polished blocks of (a) SHO coke MRLVS, and (b) PO coke MRLV.

Figure 5. Pore area distributions for SHO coke MRLVS and PO coke MRLV.

Figure 6. Petrographic images of (a) SHO coke MRLVS, and (b) PO coke MRLV. The scale bar represents $10 \mathrm{~mm}$.

Figure 7. Mean COF over time for SHO coke MRLVS and PO coke MRLV.

Figure 8. Stitched SEM image of a progressive loading scratch test in a coke MRLV sample, with examples of damage mechanisms labelled. N.B. The scratch direction was from left to right in the micrograph.

Figure 9. Main damage mechanisms by loading range and microtexture/microtextural interface for (a) SHO coke MRLVS, and (b) PO coke MRLV (see inset for legend).

N.B. The numbers on the $\mathrm{x}$-axis represent the loading force range. The $\mathrm{x}$-axis is grouped by microtexture/ microtextural interface. $\operatorname{IgC}=$ intergranular cracking, $\mathrm{TgC}=$ transgranular cracking, Delam $=$ delamination, $\mathrm{CGAP}=$ crack growth along planes, $\mathrm{SF}=$ semi-fusible and $\mathrm{Fus}=$ fusible.

Figure 10. Severity of damage by loading range and microtexture/microtextural interface for (a) SHO coke MRLVS, and (b) PO coke MRLV (see inset for legend).

N.B. The numbers on the $\mathrm{x}$-axis represent the loading force range. The $\mathrm{x}$-axis is grouped by microtexture/ microtextural interface. $\mathrm{SF}=$ semi-fusible and Fus $=$ fusible.

Figure 11. Photograph of a coke MRLVS fracture face, with examples of crack propagation mechanisms and contributory factors to the fracture labelled.

N.B. SF is an abbreviation for semi-fusible.

Figure 12. Radar graph summarising the mean values for each feature and mode of fracture propagation observed on fracture faces of SHO coke MRLVS and PO coke MRLV. 